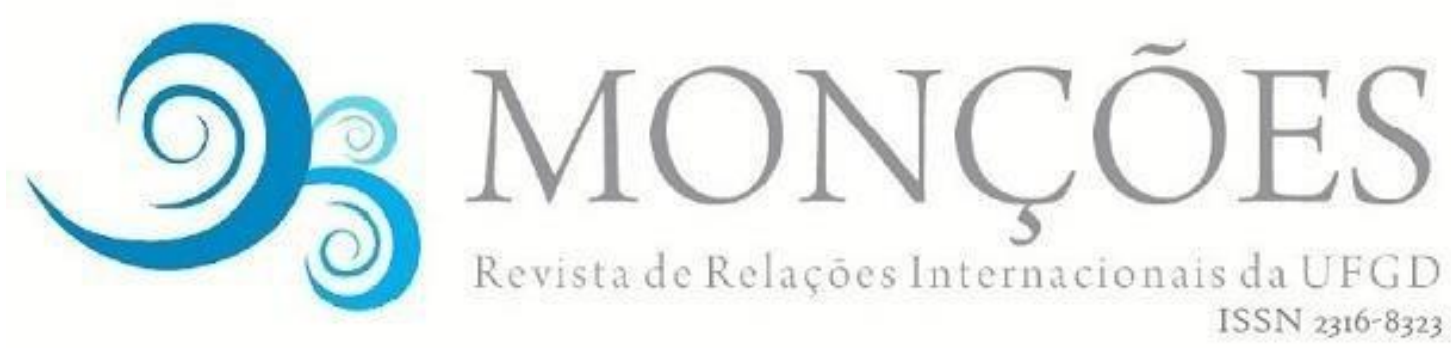

\title{
AS MULHERES NO ITAMARATY: AS REFORMAS DO MINISTÉRIO DAS RELAÇÕES EXTERIORES À LUZ DA TEORIA FEMINISTA
}

\author{
LUCIANA BRANDÃO \\ Mestranda no Programa de Pós-Graduação em Sociologia (PPGS) da UFRGS e \\ Bacharel em Relações Internacionais pela mesma Universidade.
}

TICIANA AMARAL

Mestranda no Programa de Pós-Graduação em Economia Política Internacional da UFRJ e Bacharel em Relações Internacionais pela UFRGS.

\author{
DOUGLAS FABIAN EUZEBIO \\ Bacharel em Relações Internacionais pela UFRGS.
}

\begin{abstract}
AIRTON GREGÓRIO
Graduando em Relações Internacionais pela UFRGS.
\end{abstract}

\begin{abstract}
RESUMO: No contexto atual, nota-se que o Ministério das Relações Exteriores ainda é uma instituição marcada pela desigualdade de gênero: as mulheres são sub-representadas, ocupando apenas cerca de $20 \%$ do corpo diplomático brasileiro. A partir deste contexto de assimetria, analisamos as reformas institucionais do Ministério das Relações Exteriores (MRE) entre 1930 e 1980, partindo da hipótese de que o viés sexista destas está ligado à vigente subrepresentatividade feminina nos quadros atuais desta instituição. A partir de revisão bibliográfica e da análise de documentos primários, compreende-se como as tais reformas contribuíram para transformar o Itamaraty em espaço de poder "masculinizado". Conclui-se que dois tipos de obstáculos foram decisivos para a generificação do MRE: os formais, como a proibição do ingresso da mulher na carreira de diplomata; e os informais, como a prática da "agregação".
\end{abstract}

PALAVRAS-CHAVE: Diplomacia; Mulheres; Gênero;

\section{WOMEN IN ITAMARATY: THE REFORMS IN THE MINISTRY OF FOREIGN AFFAIRS ANALYZED BY THE PERSPECTIVE OF THE FEMINIST THEORY}

\begin{abstract}
In the current context, the Brazilian Ministry of Foreign Affairs is still marked by gender inequality: women are underrepresented, counting for only $20 \%$ of the diplomatic corps. Considering this asymmetry, we analyzed the Ministry's institutional reforms between 1930 and 1980. Our hypothesis is that the sexist bias of these reforms is connected to the current low level of representation of women in this institution. By reviewing the main literature in the field of Feminist Theory and analyzing primary sources, we concluded that such reforms contributed to the masculinization of this power arena. Two main types of obstacles were decisive to gender imbalances in the Ministry of Foreign Relations: formal ones, such as laws banning women to enter the diplomatic career; and informal ones, such as the rule of "aggregation".
\end{abstract}

KEYWORDS: Diplomacy; Women; Gender; 


\section{Introdução}

Em 2014 foi fundado, dentro do Ministério das Relações Exteriores do Brasil (MRE, também denominado "Itamaraty"), um comitê para o combate à discriminação de gênero e raça (GALLO, 2014). A iniciativa foi encabeçada por um grupo de mulheres dentro do ministério que, mobilizadas, demandaram ações mais concretas para promover a igualdade de gênero dentro da instituição ${ }^{1}$. A criação do comitê acontece no âmbito de um processo mais longo no qual o Itamaraty busca promover a diversidade em seus múltiplos aspectos dentre o seu quadro de diplomatas. Exemplos de outras iniciativas que se enquadram neste projeto são o "Programa de Ação Afirmativa do Instituto Rio Branco - PAA"2, instaurado em 2002 (BRASIL, 2014) e a mais recente prática não oficializada de incentivar a promoção de diplomatas mulheres a embaixadoras (BALBINO, 2009, p.252) ${ }^{3}$.

Apesar destes esforços, o Itamaraty ainda se destaca como uma esfera de poder na qual as mulheres são sub-representadas, ocupando apenas cerca de $20 \%$ do corpo diplomático (BALBINO, 2009, p.247). Ainda que não haja um consenso sobre quais são as consequências desta sub-representação nos órgãos que formulam e praticam a política externa brasileira, é reconhecido que a ausência de mulheres nestas instituições acaba por reforçar o caráter "masculinizado"4 destes lugares, fortalecendo um círculo vicioso que deslegitima e repele a presença feminina e a feminilidade das esferas de poder.

\footnotetext{
${ }^{1}$ A instalação de uma sala de amamentação para que diplomatas com filhos pequenos não fossem prejudicadas durante o exercício do seu ofício e a realização de um mapeamento racial dos funcionários do Itamaraty são alguns exemplos de ações realizadas por este comitê.

2 Segundo o MRE, o PAA é uma iniciativa para acentuar a diversidade étnica dentro do Itamaraty por meio da concessão de bolsas de estudo para afrodescendentes. As bolsas permitem aos candidatos custearem os seus estudos para o Concurso de Admissão à Carreira de Diplomata, única forma de ingresso no MRE desde 1946.

${ }^{3}$ Viviane Balbino, diplomata brasileira, descreve em seu artigo que "há alguns anos, o Ministério vem adotando a prática, não oficial, porém não negada, de incluir pelo menos uma diplomata em cada lista de promovidos a ministros de primeira classe" (BALBINO, 2009, p.252).
}

${ }^{4} \mathrm{O}$ termo masculinizado é usado aqui pela sua relação com o termo gendered, transposto para o português como "generificado". A ideia que se busca passar é de que os espaços de interação não são neutros em termos de gênero. Pelo contrário, a forma como são socialmente construídos 
Dentro deste contexto, o presente artigo busca compreender quais são as raízes históricas desse processo de "generificação" do Itamaraty. Especificamente, busca-se explorar de que maneira as Reformas ocorridas entre as décadas de 1930 e 1980 influenciaram neste processo. Entende-se que a maneira como esta instituição foi construída ao longo do século passado engendrou estruturas oficiais (institucionalizadas em marcos legais, como decretos e leis) e não-oficiais (como práticas e costumes sociais) discriminatórias. A consequência deste processo é a sistemática exclusão das mulheres da atividade diplomática brasileira.

O artigo desenvolve-se em diálogo com os trabalhos de Guilherme Friaça (2012), Viviane Balbino (2011) e Suzeley Kalil Mathias (2009) sobre gênero e diplomacia. Sobre o referencial teórico, optou-se por utilizar a ótica das teorias feministas de Relações Internacionais (RI) para guiar o esforço analítico. Julgase que este corpo teórico, ainda que extremamente heterogêneo, ofereça um conjunto epistemológico mais adequado para a narrativa que se busca construir, pois leva em conta, além das estruturas institucionais de poder, a importância das narrativas pessoais dos atores e das atrizes envolvidos na construção do processo histórico. Os trabalhos de Cynthia Enloe (1989), J. Ann Tickner (1997) e a coletânea organizada por Laura J. Shepherd (2010) foram basilares para o desenvolvimento do argumento. Quanto às fontes primárias consultadas, constam os discursos relacionados às comissões de reforma e decretos-lei, quando disponíveis, além do mandado de segurança de Maria Sandra Cordeiro de Melo ${ }^{5}$.

insere nestes espaços características usualmente associadas a ideias pré-concebidas sobre masculinidade ou feminilidade.

${ }^{5}$ Quanto à questão das fontes primárias sobre a temática das mulheres e da diplomacia no Brasil, é importante mencionar a tese de Friaça (2012), que sistematiza o conteúdo de diversos documentos originais da época, tais como: artigos de jornais, diários, correspondências, discursos, etc. além de compilar o relato pessoal por meio de depoimentos e entrevistas de diversas pessoas envolvidas direta ou indiretamente no debate. $O$ trabalho aborda o tema desde o início do século XX até os dias atuais e oferece uma base essencial para consulta de documentos históricos, geralmente de difícil alcance para o público de pesquisadores que moram longe de Brasília e do Rio de Janeiro. 
Depois da exposição sobre o referencial teórico, analisamos as Reformas Mello Franco (1931) e Oswaldo Aranha (1938). Na seção seguinte, investigamos a reabertura às mulheres no MRE, desde a discussão em suas comissões de reforma (1951-1953), passando pelo mandado de segurança que garantiu a entrada de Maria Sandra Cordeiro de Melo (1952-1953) até a revogação da proibição (1954). Por fim, analisamos as práticas que dificultaram a superação da desigualdade de gênero no Itamaraty até a década de 1980, focando na política de "agregação" das diplomatas mulheres que se tornavam cônjuges de homens também diplomatas e acabavam excluídas do exercício de suas funções públicas.

Com este trabalho percebe-se que, em primeiro lugar, os obstáculos formais ao ingresso das mulheres intensificaram-se nos momentos em que estas demonstraram maior vontade e capacidade de ingressar no Itamaraty. Em segundo lugar, nota-se que a superação dos obstáculos formais facilitaram apenas em parte o ingresso das mulheres, pois se seguiram da instalação de outros elementos dificultadores, desta vez como obstáculos "não-formais", e por isso mais difíceis de serem combatidos. Por fim, cabe pontuar também as dificuldades enfrentadas para se ter acesso e investigar documentos primários, pouco disponibilizados pelo MRE. Espera-se que este artigo venha a contribuir para o debate sobre política externa por fornecer um histórico organizado e detalhado do período estudado e pelas explicações hipotético-dedutivas desenvolvidas para elucidar os documentos e discursos aqui analisados.

\section{Contribuições das Teorias Feministas para as Relações Internacionais}

A inclusão do ponto de vista das teorias feministas no campo de estudo das RI é um processo deveras recente, com os primeiros artigos escritos na década de 1980, momento em que a disciplina passava por uma revisão a respeito do seu objeto de estudo e dos métodos para análise - mais conhecido por "Terceiro Debate" (PAIVA, 2014, p.16; TICKNER, 2002, p.361). Nesse contexto, teóricas feministas propunham um redirecionamento do foco da disciplina tradicionalmente preocupada em analisar as relações de poder entre Estados - 
para uma análise que se preocupasse com o indivíduo e, principalmente, com a invisibilidade de determinados indivíduos nas RI. As teorias feministas sublinharam a necessidade de conduzir análises a partir de questionamentos distintos daqueles que vinham sendo feitos até então ${ }^{6}$. Dentre as novas perguntas propostas, uma das principais indagações é "onde estão as mulheres na política internacional?" (POSSAS; REIS, 2009, p.229-230).

A ausência de sujeitos femininos na literatura de RI passa, muitas vezes, como algo despercebido por quem pesquisa ou é de tal modo naturalizada nas estruturas de pensamento que deixa de ser uma questão a ser desvendada pelo esforço de pesquisa. Segundo Enloe (1990), "na maior parte das vezes, nem se percebe que os governos se parecem com clubes de homens" (p.6, tradução nossa). No estudo da política externa brasileira não é diferente. A menção a mulheres é rara - senão ausente - nas principais obras de referência acadêmica (CERVO; BUENO, 2002; MOURA, 1980). Assim, as teorias feministas contribuem ao apontar para desigualdades entre os gêneros e empreender o esforço de desnaturalizá-las.

Tradicionalmente, a preocupação com as questões de sub-representação feminina nas instituições políticas tem sido objeto de análise de um grupo específico denominado "feminismo liberal". Com origens que datam do século XVIII (OFFEN, 2012), as feministas liberais buscam compreender as razões que levam as mulheres a serem excluídas das esferas públicas e políticas, de modo a identificar estas barreiras e removê-las em prol de uma maior igualdade de oportunidades. Campanhas em prol do sufrágio universal, por exemplo, foram processos nos quais as feministas liberais estiveram ativamente engajadas (WHITWORTH, 2008, p. 393).

É curioso observar como a entrada das mulheres brasileiras na vida pública deu-se de modo paradoxal. Conforme explorado na próxima seção, nota-se que as mulheres conquistaram o direito ao voto e ingressaram formalmente no

\footnotetext{
${ }^{6}$ As teorias feministas de relações internacionais são, no entanto, muito mais diversificadas entre si do que este artigo permite adereçar. Para uma visão geral sobre as diferentes correntes teóricas e os debates entre elas, ver: Paiva (2014) e Hansen (2010).
} 
mercado de trabalho ao mesmo tempo em que foram proibidas por lei de ingressar na carreira de funcionárias públicas do MRE. Fica claro que a conquista de oportunidades mais igualitárias em determinadas instituições não pressupõe, necessariamente, avanços em todas as esferas de poder.

A noção de separação entre as esferas do público e do privado ajuda a compreender porque as mulheres não têm acesso pleno às instituições políticas. Segundo teóricas feministas, as noções de público e privado teriam sido construídas uma em oposição à outra, a partir de uma visão de mundo dual, assim como as noções de gênero. Diferente da ideia de "sexo", que está relacionada somente aos aspectos biológicos do que significa ser um homem ou uma mulher, a categoria de gênero é melhor compreendida como "o conjunto de características culturalmente definidas e socialmente construídas" que, dentro de determinado discurso, cria significações sobre o que é masculino e o que é feminino (TICKNER, 2002, p. 383, tradução nossa). Por consequência, além de divididas, estas esferas também teriam sido construídas baseadas sobre pressupostos que acabam por definir quem deveria ocupar cada um destes espaços. De um lado, a esfera do privado enquanto arena da domesticidade, da reprodução social e das relações pessoais - e das mulheres. Do outro, o público, local das atividades políticas, econômicas e da guerra - exercidas por homens (POSSAS; REIS, 2002, p. 230-232). Percebe-se que as esferas públicas de poder são espaços geralmente masculinizados e, portanto, adversos à participação feminina. As teorias feministas problematizam a ideia de que estas divisões são naturais e, a partir daí, buscam compreender o porquê da ausência de mulheres como sujeitos de RI.

Análogas às instituições formuladoras de política, aquelas relacionadas à guerra também refletem o mesmo fenômeno de exclusão sistemática das mulheres. As Forças Armadas são outro exemplo de uma arena de poder masculinizada central para as RI. O que se percebe ao pesquisar sobre 0 processo de ingresso das mulheres nessa instituição é que os homens inseridos nestes espaços se sentem desconfortáveis e ameaçados diante da feminilização destes ambientes. Carreiras (2009) explora algumas possíveis explicações para este fenômeno a partir do estudo específico das Forças Armadas portuguesas e 
holandesas. Ao ser entrevistado, o ex-chefe de estado-maior das Forças Armadas dos Estados Unidos, comenta que "o influxo de mulheres trouxe maiores transformações às Forças Armadas americanas que a introdução de armas nucleares" (CARROL; HALL 1993 apud CARREIRAS, 2009, p.170). A percepção expressa em sua fala assinala como a presença feminina em espaços masculinizados gera uma série de desconfortos. As conclusões são valiosas e podem, em grande medida, ser utilizadas para basear investigações sobre outros organismos de poder similares, como é o caso do MRE. Sobre a esfera governamental, a autora Cynthia Enloe (1990) explica que este desconforto se dá, em grande parte, porque a presença das mulheres em meio a estruturas dominadas por homens acaba por revelar a estranheza deste padrão e, mesmo que não intencionalmente, denunciam a desigualdade de gênero e desnaturalizam as divisões sociais entre feminino e masculino.

No entanto, resta a dúvida de como estes espaços públicos e políticos teriam historicamente se concretizado como estruturas masculinizadas. As teorias feministas contribuem para a análise permitindo que se vá além da explicação simplista de que as instituições são um mero produto do seu tempo. É possível argumentar que o Itamaraty, por exemplo, seria este espaço masculinizado porque foi gestado em uma sociedade patriarcal e machista, a qual só começaria a ser mais sistematicamente contestada no último quartel do século XX. No entanto, este tipo de argumento reducionista serve para encobrir as intenções que guiaram as ações dos sujeitos políticos e acaba por minar 0 esforço de pesquisa. Em última instância, esse tipo de argumentação impede que sejam revelados os mecanismos construtores das engrenagens institucionais que consolidaram as relações de poder assimétricas vivenciadas ainda hoje em dia.

Outra possível explicação para o porquê de as mulheres não terem participado mais da formulação de política externa no Brasil é a que aponta para um desinteresse por parte da população feminina. Nesta categoria de argumentos, destaca-se a ideia de que as diferenças biológicas entre homens e mulheres desqualifica as mulheres para atuarem como diplomatas, seja porque 
mulheres não possuem determinados atributos necessários ao (ou porque possuem certas características incompatíveis com o) exercício da diplomacia.

Uma terceira abordagem baseada na ótica proposta pelas teorias feministas sugere que se busque desvendar o modo como as hierarquias de gênero acabam servindo para reforçar instituições e práticas desiguais (TICKNER, 1997, p. 200). Enquanto expectativas diferentes recaem sobre homens e mulheres a respeito dos papéis a serem desempenhados na vida social, instituições políticas como o MRE historicamente se construíram reforçando estes pressupostos.

É dentro desta proposta de agenda de pesquisa que o presente trabalho se insere. A análise sobre as reformas do Itamaraty à luz da teoria feminista permitirá melhor compreender como as hierarquias de gênero se estruturam dentro desta instituição, construindo o Itamaraty como uma esfera de poder masculinizada e edificando as barreiras quase invisíveis existentes ainda hoje, que dificultam a entrada de mulheres e inibem uma possível "desmasculinização" deste espaço. A próxima seção irá investigar a gênese desta construção formal de barreiras, analisando o ingresso das primeiras mulheres no Itamaraty e a subsequente proibição formal à entrada delas.

\section{As reformas da década de 1930 e a proibição do ingresso de mulheres no MRE}

Nos anos 30, o Estado brasileiro passou por uma ampla reorganização em diversos âmbitos, além da quebra com a tradição imperial que sobrevivera parcialmente durante a Primeira República. Neste rearranjo o Itamaraty sofreu duas grandes reformas correlatas, uma em 1931 e outra em 1938. Tais mudanças incrementais e radicais, segundo Cheibub (1985), foram fundamentais para a coesão da instituição e consequente execução de suas 
funções ao longo do século XX7. No entanto, a reforma de 1938 também trouxe um retrocesso significativo em pleno progresso da organização social e política do país: a proibição da entrada de mulheres nos quadros do MRE. Para entender como se dá esta decisão, é importante recuperar brevemente o contexto histórico em que vinham ocorrendo as transformações dos direitos das mulheres bem como as mudanças pelas quais passava o Itamaraty naquela época.

3.1 Os antecedentes à proibição formal: a desbravadora Maria José de Castro Rebelo Mendes no contexto de um Brasil patriarcal

Embora alguns países tenham instituído o voto feminino na segunda metade do século XIX, a grande expansão do sufrágio se deu na primeira metade do século XX. No Brasil, o Rio Grande do Norte foi o primeiro estado a permitir o registro e eleição de mulheres, em 1927, sendo o sufrágio feminino nacional instituído em 1932 pelo Código Eleitoral brasileiro. Em 1934, ele foi formalmente adicionado à nova Constituição Federal

Um pouco antes destas mudanças, em 1918, o Brasil aceitou a primeira candidatura de uma mulher em concurso para cargo público em um ministério (FRIAÇA, 2012, p.11-29; BERNARDES, 2013). Maria José de Castro Rebello Mendes, dez anos antes do primeiro registro feminino para votar no Brasil, conseguiu, sob a gestão do chanceler Nilo Peçanha, a permissão de participar do concurso à carreira de Secretaria de Estado do Itamaraty, no qual ficaria em primeiro lugar. O caso de sua inscrição gerou comoção, tendo sido defendido por Rui Barbosa e levado até o Presidente da República. Segundo Bernardes (2013), já na época houve, na opinião pública em geral e do Itamaraty em particular, resistência à entrada da mulher na vida pública oficial, a despeito de

\footnotetext{
${ }^{7}$ Como exemplo de progresso, citamos a fusão das carreiras do ministério, que deram uma coesão ímpar às políticas do serviço exterior; reorganização das condições materiais do ministério, superando o patrimonialismo até então vigente, no qual os pagamentos e posses das representações no exterior se confundiam com os do representante; a criação da Comissão de Promoções e Remoções e políticas correlatas, afim de tornar a carreira mais meritória (CHEIBUB, 1985).
} 
eventuais reconhecimentos e elogios. O próprio chanceler Nilo Peçanha, após autorizar a participação de Maria José no concurso público, teria adicionado que "melhor seria, certamente, para o seu prestígio que continuasse na direção do lar" (FRIAÇA, 2012, p.13).

Essencial para permitir a inscrição de Maria Rebello no concurso público foi a lei vigente à época, a qual não versava nada específico sobre a participação das mulheres em concursos públicos. Conforme defendido por Rui Barbosa, "não [havia] na legislação pátria dispositivo algum que incapacitasse as mulheres para o exercício das funções administrativas" (FRIAÇA, 2012, p.14).

Após o ingresso de Maria Rebello, que criou o precedente jurídico e abriu as portas do Itamaraty para a candidatura e ingresso de outras mulheres, outras dezoito mulheres adentraram o Itamaraty, entre 1919 e 1938. Este processo ocorreu tanto pela via do concurso quanto por transferência de outros órgãos. No entanto, o ingresso das mulheres foi interrompido no ano de 1938, quando uma nova lei vetou oficialmente o acesso delas ao Ministério (FRIAÇA, 2012, p. 4).

3.2 A primeira proibição formal às mulheres diplomatas: a Reforma Mello Franco e Oswaldo Aranha

Com a Revolução de 1930, o Estado brasileiro deu início a um processo de modernização, focada na centralização e burocratização da administração pública, implementando-se uma estruturação das carreiras civis e padronizandose os serviços. Nesse contexto de reformas, ainda no âmbito do Governo Provisório de Getúlio Vargas, o chanceler Afonso de Mello Franco empreende uma reforma em 1931, disposta no Decreto no 19.592. Até então, o MRE contava com três carreiras distintas: Corpo Diplomático, Corpo Consular e Secretaria de Estado. Ao suprimir a carreira da Secretaria de Estado, incorporando seus funcionários às outras duas, a Reforma Mello Franco inicia o processo de fusão para o Quadro Único do Itamaraty, o que atinge diretamente o processo de recrutamento de diplomatas (FRIAÇA, 2012, p.39-40). 
A principal consequência desta reforma foi incorporar as mulheres que pertenciam à Secretária de Estado exclusivamente ao Corpo Consular, negando sua participação no Corpo Diplomático ${ }^{8}$. Esta divisão intencional foi um dos primeiros instrumentos formais utilizados para "masculinizar" a esfera da diplomacia. O corpo consular e diplomático diferiam tanto no grau de importância que Ihes era atribuído quanto nas suas capacidades de influenciar na formulação de política externa e de atuar no exterior. Em ambos os casos, a carreira diplomática era considerada de maior prestígio e dignidade que a consular. Os postos consulares, por sua vez, operavam em condições de maior isolamento e menor conforto, além de exigir uma preparação técnica mais sólida e não promover o serviço no estrangeiro, conforme diferenciado pelo MRE à época (FRIAÇA, 2012, p.40).

Em 1938, o chanceler Oswaldo Aranha realizou mais uma reforma, aprofundando aquela de Mello Franco. Entre outras disposições, a reforma conclui a fusão das carreiras do Serviço Consular e do Serviço Diplomático e, ao mesmo tempo, proibiu oficialmente a entrada de mulheres no Itamaraty. A Reforma Oswaldo Aranha foi contra uma tendência progressista na igualdade de gêneros que vinha desde 1918 e que se intensificara em 1932, com o sufrágio feminino limitado garantido pelo Código Civil. Estava formalizada a política mais expressamente sexista do MRE, impactando de forma profunda na constituição do Ministério como espaço de poder masculinizado. O Itamaraty ainda sustentaria por 15 anos tal quebra na igualdade dos gêneros.

A luta pela incorporação das mulheres no serviço público teve na década de 30 uma sucessão de medidas contraditórias representadas por decretos-lei e portarias que ao mesmo tempo impulsionavam a participação dessas na esfera pública e, depois, eram seguidos por outros que delimitavam sua inserção. Percebe-se, analisando a evolução institucional da época, uma estratégia

\footnotetext{
${ }^{8}$ Destaca-se o caso da funcionária do MRE Wanda Vianna Rodrigues, que foi transferida para a carreira consular em 1931 devido à reforma Mello Franco a quem foi negada formalmente a promoção por tempo de carreira para um posto no corpo diplomático devido ao "princípio de que as mulheres não podem ingressar na carreira diplomática", devendo servir exclusivamente no corpo consular (FRIAÇA, 2014, p.30).
} 
deliberada de restringir o progresso da equidade de gênero quando este alcançava as esferas mais altas da administração pública. Ainda assim esses retrocessos conservadores estimularam as mulheres a lutarem e reivindicarem sua participação na vida pública, como o exemplo de Maria Sandra Cordeiro de Melo que relataremos a seguir. Esta levou seu caso à esfera jurídica depois de ter sua inscrição para o MRE revogada por questão de gênero nos anos 50 .

\section{Reconquistando os espaços masculinos: o reingresso das mulheres em} 1953

Em 1952, em meio às discussões internas sobre a nova reforma do MRE e consequente reabertura às mulheres, a baiana Maria Sandra Cordeiro de Melo entrou com uma liminar via Ministério Público contra o MRE alegando a inconstitucionalidade da legislação que restringia o ingresso de mulheres no concurso, que desde 1946 se tornara responsabilidade exclusiva do Instituto Rio Branco. Após deferimento da causa, prestação do concurso e entrada de Maria Sandra no Ministério em 1953, a proibição às mulheres foi finalmente revogada em 1954.

Pode-se evocar uma série de fatores conjunturais à época para buscar entender o contexto sob o qual seu mandado de segurança foi aceito e resultou na alteração do regulamento do concurso no período que se sucedeu - entre 1952 e 1954. À primeira vista, embora Maria Sandra tenha buscado na Constituição seu embasamento jurídico, a institucionalização das ideias feministas no Ocidente tornaram a situação muito mais propícia à mudança proposta pela candidata.

A Carta da ONU, assinada em São Francisco em 1945, e a Declaração Universal dos Direitos Humanos, assinada em Genebra em 1948, formularam as primeiras vias de legitimação do enfoque feminista nas instituições, reafirmando a necessidade de se estimular 0 respeito às liberdades fundamentais e a igualdade de oportunidades sem distinção de raça, sexo, língua ou religião (ONU, on-line, p.5; UNIC, 2009, p.5). No âmbito institucional, a demanda pela 
reinserção da mulher no MRE encontra seu espaço no movimento por uma reforma administrativa geral a partir de 1951. Para esse fim o Ministro João Neves constituiu a Comissão de Elaboração Final do Projeto de Reforma do Ministério das Relações Exteriores, em 1952 (CASTRO, 2009, p.451). Na comissão, um dos pontos sobre os quais os conselheiros deveriam emitir parecer era o retorno das mulheres à carreira diplomática. Um dos convidados, Roberto Campos, versando sobre o tema, opinou:

A favor, existem as inclinações e faculdades essenciais típicas do elemento feminino e para os quais a Diplomacia fornece campo abundante. Para dificuldades de contatos, de relações delicadas, 0 elemento feminino é adequado. O segundo aspecto é o terreno linguístico, em que as mulheres revelam muito de sua superioridade sobre o elemento masculino (BANDEIRA DE MELO, 1982, p.85 apud BALBINO, 2011).

A fala de Campos ajuda a compreender como a reinserção da mulher na carreira diplomática, mesmo quando encarada como algo positivo, ainda ficava restrita à visão tradicional sobre a divisão dos papéis de gênero, atribuindo às mulheres características como delicadeza e adequação. Ou seja, a validade da presença das mulheres na carreira diplomática não se dava por um reconhecimento da sua agência e capacidade política, mas se restringia às suas "típicas" faculdades femininas. Assim, mesmo que houvesse uma proposta de abertura ao reingresso de mulheres, este processo não parecia compartilhar de uma percepção do Itamaraty como espaço de poder masculinizado e muito menos que devesse ser reformado em suas bases para promover uma maior igualdade de gênero dentro da instituição. Algumas vozes, por outro lado, destacaram a relevância da mulher no MRE, apontando-as como elemento com grande potencial para quebras necessárias de paradigma. Conforme exposto pelo Dr. Arízio Viana, haveria "muitas mulheres que revelam nesta competição, em que há tantos fatores de corrupção, certas condições que nos dão esperança de uma renovação de costumes e melhoria no padrão e na eficiência dos trabalhos públicos." (BANDEIRA DE MELO, 1982, p.85 apud BALBINO, 2011).

A Comissão teve seu relatório aprovado unanimemente, sendo mais tarde encaminhado ao Ministro em 20 de maio de 1953, acompanhado de um Projeto de Lei, de um Projeto de Decreto e seus respectivos anexos (CASTRO, 2009, 
p.451). Entre outros pontos abordados, o Relatório manifestou-se favorável "(...) ao ingresso de mulheres na carreira, desde que adotadas medidas destinadas à ampliação da área de recrutamento dos candidatos ao Instituto Rio Branco" (p.454-455). No entanto, não teve prosseguimento o Projeto de Lei que acompanhou o Relatório de 1953 e que sugeriu a adoção da estrutura organizacional acima indicada (CASTRO, 2009, p.456-7).

Nesse contexto de reformas, o conflito constitucional em termo jurídico gerado por Maria Sandra Cordeiro de Melo expôs a incoerência da diferenciação de gênero no ingresso do concurso. Dois anos depois do recurso enviado por Maria Sandra, a alteração necessária para oficializar o reingresso da mulher no MRE foi promulgada. Uma vez aceita no Itamaraty, a baiana tornou-se motivo de inspiração para mulheres brasileiras que antes sequer aspiravam à carreira diplomática, tanto pela tradição do âmbito político masculino como por seguirem uma trajetória profissional que quase sempre as distanciava do serviço público de alto escalão. A despeito das dificuldades, em janeiro de 1954, a alteração tornou-se a Lei Federal № 2.171 versando que "ao ingresso na classe inicial da carreira de Diplomata são admitidos os brasileiros natos, sem distinção de sexo, nos termos e observadas as demais condições do Decreto-lei de número 9.032, de 6 de março de 1946."

\section{Obstáculos não-formais: as embaixadoras agregadas e o sexismo velado.}

Nos capítulos anteriores, demonstrou-se como as reformas do MRE engendraram mecanismos que formalmente impediram as mulheres de participarem da diplomacia brasileira. Estas barreiras foram erguidas por vias legais, primeiro com o Decreto-lei no19.592 de 1931 e, em um segundo momento, com o Decreto-lei no 179 de 1938. Quando estas leis foram revogadas 
em $1954^{9}$, a proporção representada pelo sexo feminino na carreira das relações exteriores aumentou gradualmente, totalizando uma média de $15 \%$ de ingressos até 1988 (FRIAÇA, 2012, p.118).

No entanto, outras práticas perpetuadas dentro do MRE também contribuíram para construí-lo enquanto espaço de poder generificado. Segundo Friaça (2012, p.118), "ainda persistiam entraves burocráticos e legais ao pleno exercício da profissão pelo sexo feminino". O mais importante destes entraves devido aos seus efeitos diretos sobre a vida das funcionárias da época - é a prática da "agregação". Em suma, esta ditava uma série de situações em que os(as) funcionários(as) deixariam de receber seu salário, incluindo a ocasião em que se um(a) diplomata casasse com outro(a) diplomata, um deles seria obrigado(a) a abrir mão do seu salário.

A instituição da agregação ocorreu por meio do Decreto-lei n.69, de 1966. Conforme o texto oficial:

Art. $5^{\circ} \mathrm{O}$ ocupante de cargo da carreira de Diplomata, temporariamente afastado de suas funções, nos casos previstos no artigo seguinte, será considerado agregado. Art. 6 São motivos de agregação, para os efeitos do presente Decreto-lei: [...] afastamento do exercício do cargo para acompanhar o cônjuge, funcionário da carreira de Diplomata, removido para pôsto no exterior (BRASIL, 1966).

O caso descrito no artigo acima foi o recurso institucional pelo qual um maior número de mulheres se afastou da carreira diplomática, especialmente quando comparado com a proporção relativa de homens que agregavam devido a esta cláusula específica. Nota-se, daí, um desequilíbrio que acabou afetando a carreira de pelo menos 15 mulheres ao longo das décadas de 60 e 70 (FRIAÇA, 2012, p.120). Ao pensarmos que em 1970 um total de 61 mulheres integravam a carreira do MRE (FRIAÇA, 2012, p.118), isto significa que pelo menos $25 \%$

\footnotetext{
${ }^{9} \mathrm{O}$ processo deu-se por meio da Lei 2.171, de 18 de janeiro de 1954, conforme informado no capítulo anterior.
} 
destas funcionárias foram temporariamente afastadas de suas funções sem direito de receber remuneração, contagem por tempo de serviço, nem promoção.

É importante notar que a prática da agregação não foi concebida em um vácuo histórico. Na realidade, questões relacionadas ao gerenciamento do casamento entre funcionários do MRE já vinham sendo alvo de discussão desde a época de Maria Rebello. Quando a primeira mulher a ingressar no Itamaraty se casou com outro funcionário do MRE, em 1922, requisitou licença diversas vezes para acompanhar o marido em suas viagens, suscitando dúvidas entre os quadros dirigentes da instituição sobre como compatibilizar os serviços dos cônjuges (FRIAÇA, 2012, p.28). A resposta para tal questionamento viria em 1934, com o Decreto 24.113, o qual determinava que em caso de matrimônio entre funcionário e funcionária dos serviços diplomáticos, um dos cônjuges deveria passar para o status de "disponibilidade não remunerada, consoante declaração escrita em que ambos manifestem a preferência do casal sôbre qual dos cônjuges deve ser atingido por essa medida" (BRASIL, 1934). Surgia, aí, as origens da prática de agregação ${ }^{10}$.

Posteriormente o Decreto-lei 9.202, de 26 de abril de 1946, passaria a exonerar do seu cargo a servidora pública que se casasse com integrante da carreira diplomática (FRIAÇA, 2012, p.37; BRASIL, 1946). Abertamente sexista, este Decreto-lei institucionalizava a desigualdade entre homens e mulheres a partir de noções pré-concebidas de gênero e função social. Assim, as estruturas sociais patriarcais ganham corpo legal e se auto legitimam a partir da força das instituições. Em suma, a criação deste Decreto-lei reafirmou o pressuposto patriarcal de que, em um casamento, a mulher deveria ser sempre a pessoa a quem caberia a obrigação de abdicar da sua vida profissional. Pode-se dizer que esta legislação contribuiu para a construção de uma cultura sexista no âmbito dos espaços públicos de poder, tal qual o Itamaraty.

\footnotetext{
${ }^{10}$ Destaca-se a linguagem não-sexista da legislação, importante avanço, principalmente quando considerados os retrocessos que aconteceriam na década de 40. É importante ressaltar que a redação final do artigo dava ao casal a capacidade de arbítrio, ainda que, como visto, na prática as mulheres fossem as quais acabassem abrindo mão de sua remuneração,
} 
É nesta esteira que se institucionaliza formalmente a prática da agregação em 1966. A autora Viviane Balbino, após realizar uma série de entrevistas com funcionárias e ex-funcionárias do MRE, aponta para este viés da prática de agregação, ainda que este não seja explícito:

\begin{abstract}
Até meados dos anos 80, o Itamaraty impunha que, no caso de casal de diplomatas, se houvesse remoção, uma das partes deveria agregar, isto é, acompanhar o cônjuge sem direito a remuneração e sem direito a que o tempo no exterior contasse como tempo de serviço. Quase na unanimidade dos casos, quem agregava era a mulher diplomata, que ficava com sua carreira estagnada enquanto seu marido progredia. Com isso, a ascensão profissional das diplomatas era virtualmente impossível, se fossem casadas com um diplomata, o que não é, absolutamente, incomum (BALBINO, 2011, p.51).
\end{abstract}

Esta prática aponta para outro fator que contribuía para a evasão das mulheres do MRE, no caso, o desafio de ter de optar entre a vida familiar e a vida profissional. Ainda que o Decreto-Lei 69 seja formalmente isento quanto à diferenciação entre os sexos, não determinando qual dos cônjuges que deveria agregar na ocasião do matrimônio - se o marido ou a esposa - é importante considerar o momento histórico em que a legislação havia sido estabelecida e o contexto social no qual estas relações operavam. No caso do Brasil da década de 60 e 70, as estruturas que regiam as dinâmicas das interações sociais eram majoritariamente patriarcais ${ }^{11}$. Conforme definido no Código Civil vigente na época de 1916 o homem era "o chefe da sociedade conjugal" enquanto a função da mulher era a de ser "companheira, consorte e colaboradora do marido nos encargos de família" (BRASIL, 1916). Este modo como ainda era concebido o papel da mulher e do homem tornava quase impensável uma situação em que 0 marido abdicasse da sua carreira em prol da ascensão profissional de sua esposa.

\footnotetext{
${ }^{11}$ Céli Pinto analisa que o momento político vivido pelo Brasil à época, no caso uma ditadura repressora, contribuiu para deslegitimar e enfraquecer os movimentos feministas. Enquanto em outras partes do mundo as mulheres avançavam na luta por uma maior igualdade de direitos, no Brasil do regime militar qualquer manifestação feminista era considerada política e moralmente perigosa, o que acaba por reforçar as feições patriarcais da sociedade brasileira (PINTO, 2010, p.16-17).
} 
Isto não significava que a decisão fosse mais fácil ou "natural" para as mulheres. Como as teorias feministas argumentam, conforme detalhado na primeira seção deste trabalho, os papéis de gênero são compreendidos como construtos sociais. Assim, discursos que tendem a naturalizar práticas desiguais, justificando que determinado sexo é mais apto para um tipo de atividade do que outro, escondem amarras de poder que perpetuam injustiças. O caso de Maria Sandra Cordeiro de Melo é emblemático: após derrubar a barreira formal do patriarcado e tornar-se a primeira mulher a ingressar no Itamaraty após um hiato de 15 anos, a funcionária foi agregada em 1970. Ela mudou-se para Ancara para acompanhar o marido - também diplomata - e, cinco anos depois, acometida por depressão, cometeu suicídio (FRIAÇA, 2012, p.113).

Deste modo percebe-se que, conquanto a entrada de mulheres para a carreira diplomática estivesse oficialmente legalizada desde a década de 1950, a prática da agregação funcionava como um fator limitador da participação feminina na formulação da política externa brasileira. Em última instância, a opção pela carreira diplomática significava ou uma renúncia à vida pessoal da mulher ou o seu fracasso como indivíduo profissional. Esta dicotomia de funções sociais, engendrada socialmente $\mathrm{e}$, inclusive, institucionalizada em leis durante a primeira metade do século XX, contribuiu para manter as mulheres afastadas da vida diplomática. Já quando elas estavam inseridas nesta esfera, a falsa dicotomia sexista e as práticas que a promoviam acabaram por dificultar o avanço profissional e empurrar as mulheres do Itamaraty para a estagnação.

A partir da década de 1980, com o processo de redemocratização, começaram a ocorrer mudanças no ingresso de mulheres à carreira diplomática. Em 1985 a prática da agregação foi flexibilizada. A partir deste momento o casal de diplomatas passava a poder trabalhar junto no exterior contanto que só uma das partes recebesse o salário integral; ao outro cônjuge cabia receber apenas um salário parcial, em torno de 1/3 a menos do que o montante total. A lógica utilizada pela administração era a de que já que o casal habitava na mesma residência não precisaria receber a parte do salário atribuída à representação (MAIA; ALVARENGA, 2010). No entanto, a imagem das instituições diplomáticas como tradicionalmente masculinas e as dificuldades que a profissão impõe à 
constituição de uma família, tornavam - e muitas vezes ainda tornam - a carreira diplomática pouco atrativa às mulheres.

\section{Conclusão}

Com o nosso olhar de uma era mais democrática e igualitária, é difícil entender o aparente paradoxo que teria se estabelecido a partir da década de 1930. Ao mesmo tempo em que os avanços do movimento pela inserção das mulheres nas instituições públicas se solidificavam, por meio da consolidação do direito ao voto, por exemplo, outras portas Ihes eram fechadas, como fica claro com a proibição do ingresso de mulheres na carreira diplomática. Esperava-se que os avanços obtidos pela igualdade de gêneros contagiassem outras esferas de poder. Conforme analisado aqui percebe-se que, contra intuitivamente, isto não ocorreu.

Ao final, o progresso feminista encarou um movimento reacionário, particularmente no Itamaraty, instituição de cunho tradicional. A proibição formal ao ingresso das mulheres neste ministério decretada por lei parece menos um paradoxo e mais um efeito colateral esperado no contexto de uma quebra extremamente recente no estado das coisas. A principal consequência do erguimento destes obstáculos formais foi a solidificação do Itamaraty como um espaço de poder masculinizado e a instalação de barreiras não-formais, que continuariam a existir mesmo após a retirada da proibição por lei.

Conforme o sociólogo Pierre Bourdieu aponta no prefácio à edição alemã do seu livro A dominação masculina:

É preciso realmente perguntar-se quais são os mecanismos históricos que são responsáveis pela des-historicização e pela eternização das estruturas da divisão sexual e dos princípios de divisão correspondentes [...] aquilo que, na história, aparece como eterno não é mais que o produto de um trabalho de eternização que compete a instituições interligadas (BOURDIEU, 2002, p.1). 
Buscamos com este trabalho evidenciar e tentar compreender justamente como se deu este "trabalho de eternização" da dominação masculina no âmbito do Ministério das Relações Exteriores no Brasil. A análise dos processos apresentada aqui nos permitiu perceber que as hipóteses reducionistas e naturalistas não dão conta de explicar a exclusão das mulheres do MRE. O argumento de que a ausência de mulheres da diplomacia seria apenas um espelho da sociedade patriarcal e machista de seu tempo não se sustenta, pois como vimos as transformações nas legislações mais gerais já vinham apontando para um caminho progressivo de maior abertura às mulheres.

Por outro lado, a falsa ideia naturalista de que as mulheres não teriam a aptidão ou o interesse na carreira diplomática também se desqualifica. Não só a disposição à carreira diplomática ficou evidente pelas crescentes inscrições e aprovações nos exames de entrada quando estes estavam disponíveis como a permanência e o trabalho contínuo destas mulheres mostra que a ideia de uma "inaptidão feminina" não se sustenta. Conforme Enloe aponta, "foi necessário poder para manter as mulheres fora dos corpos diplomáticos de seus países" (1990, p.353, tradução nossa). O que este trabalho nos permitiu identificar foi justamente que tipo de poderes que foram necessários no caso brasileiro e, mais ainda, como eles se articularam.

Concluímos que, embora não exista uma resposta única e concreta sobre por que permanece, ainda hoje, a baixa representatividade feminina no MRE, as leituras realizadas e do levantamento de dados apontam para um caminho explicativo que esclarece parcialmente como se deu a marginalização das mulheres neste espaço institucional estatal. As barreiras à inserção das mulheres no Itamaraty, mencionadas ao longo do artigo, foram levantadas tanto por vias formais - como reforma Mello Franco de 1931, que delimitava a sua participação ao Corpo Consular e proibia legalmente o ingresso feminino à carreira diplomática em 1938 - quanto por vias informais, tal qual a prática de agregação.

Em suma, a forma como o Itamaraty foi engendrado glorifica e, portanto, beneficia determinados comportamentos tipicamente compreendidos como 
"masculinos". Isto cria barreiras à entrada de sujeitos "femininos" impedindo ou, ao menos, dificultando sobremaneira - a plena atuação política das mulheres. Assim, menos mulheres participam das tomadas de decisões o que acaba por reforçar o caráter masculinizado dos espaços, retroalimentando o ciclo de desigualdade. Este trabalho mostrou que, apesar da oposição patriarcal e machista, as mulheres enfrentaram ao longo de todo o século $X X$ o poder discriminatório, buscando e encontrando maneiras de derrubar os obstáculos quando estes foram soerguidos. Infelizmente, alguns deles ainda se mantêm na atualidade.

Para superarmos as barreiras contemporâneas, é imprescindível que o MRE siga, dentro de seus planos institucionais, incentivando a inclusão das mulheres, via ações afirmativas ou mesmo por canais de diálogo não formalizados, mostrando seu interesse em democratizar a formulação de política externa ao inserir uma visão mais feminina em seus quadros diplomáticos. A entrada de mais mulheres e sua articulação possibilitaria transformar a imagem do Ministério das Relações Exteriores como arena de poder masculina, possibilitando assim um exercício da diplomacia revestido de um caráter menos masculinizado e promovendo uma política externa mais diversa em seu etos. 


\section{Referências Bibliográficas}

BALBINO, Viviane. Diplomata: substantivo de dois gêneros. Brasília: Fundação Alexandre de Gusmão, 2011.

BALBINO, Viviane. A Presença da mulher na diplomacia brasileira no início do século XXI. In: MATHIAS, Suzeley Kalil (Org.). Sob o signo de Atena: gênero na diplomacia e nas Forças Armadas. São Paulo: Editora UNESP, 2009.

BERNARDES, Maria Elena. Tensões e desafios do feminino nos consagrados espaços masculinos. Seminário Internacional Fazendo Gênero 10 (Anais Eletrônicos), $\quad$ Florianópolis, 2013. Disponível em: <http://www.fazendogenero.ufsc.br/10/resources/anais/20/1386548830_ARQUI VO_MariaElenaBernardes.pdf>. Acesso em: 10 nov. 2014.

BOURDIEU, Pierre. A dominação masculina. Rio de Janeiro: Bertrand, 2002.

BRASIL. Lei no 7.501 de 27 de junho de 1986. In: SARNEY, José; SODRÉ Roberto Costa de Abreu. Regulamento pessoal serviço exterior. Acesso em: 10 nov. 2014.

BRASIL. Lei № 3.071 , de $1^{\circ}$ de janeiro de 1916. Presidência da República, Casa Civil, Subchefia para Assuntos Jurídicos. On-line. Disponível em: <http://www.planalto.gov.br/ccivil_03/leis//3071.htm>. Acesso em: 10 nov. 2014.

BRASIL. Decreto n 21.411, de 17 de maio de 1932. Presidência da República, Casa Civil, Subchefia para Assuntos Jurídicos. On-line. Disponível em: <http://www.planalto.gov.br/ccivil_03/decreto/1930-1949/D21411.htm>. Acesso em: 10 nov. 2014.

BRASIL. Decreto № 24.113, de 12 de abril de 1934. Câmara Legislativa. On-line. Disponível em: http://www2.camara.leg.br/legin/fed/decret/1930-1939/decreto24113-12-abril-1934-505019-publicacaooriginal-1-pe.html. Acesso em: 10 nov. 2014.

BRASIL. Decreto-lei n 5452 de 1 de maio de 1943. Presidência da República, Casa Civil, Subchefia para Assuntos Jurídicos. Disponível em: <http://www.planalto.gov.br/ccivil_03/decreto-lei/Del5452.htm>. Acesso em: 10 nov. 2014.

BRASIL. Decreto-lei n 9.202, de 26 de abril de 1946. Presidência da República, Casa Civil, Subchefia para Assuntos Jurídicos. On-line. Disponível em: <http://www.planalto.gov.br/ccivil_03/decreto-lei/1937-1946/Del9202.htm>.

Acesso em: 10 nov. 2014.

BRASIL. Lei no2171, de 18 de janeiro de 1954. Câmara Legislativa. On-line. Disponível em: <http://www2.camara.leg.br/legin/fed/lei/1950-1959/lei-2171-18janeiro-1954-361602-norma-pl.html>. Acesso em: 10 nov. 2014.

BRASIL. Decreto-Lei $\mathrm{n}^{\circ} 69$, de 21 de novembro de 1966. Presidência da República, Casa Civil, Subchefia para Assuntos Jurídicos. On-line. Disponível em: <http://www.planalto.gov.br/ccivil_03/Decreto-Lei/1965-1988/Del0069.htm>. Acesso em: 10 nov. 2014. 
BRASIL. Ministério das Relações Exteriores. Programa de Ação Afirmativa do Instituto Rio Branco - PAA. On-line. Disponível em: $<$ http://www.institutoriobranco.mre.gov.br/pt-

br/programa_de_acao_afirmativa.xml>. Acesso em: 09 nov. 2014.

BRASIL. Constituição de 1988. Constituição da República Federativa do Brasil. Brasília, DF: Senado Federal: Centro Gráfico, 1988.

CARREIRAS, Helena. O Olhar dos Homens: resistência e cumplicidade nas respostas masculinas à integração de mulheres nas forças armadas. In: MATHIAS, Suzeley Kalil (Org.). Sob o signo de Atena: gênero na diplomacia e nas Forças Armadas. São Paulo: Editora UNESP, 2009.

CASTRO, Flávio Mendes de Oliveira. Dois séculos de história da organização do Itamaraty (1808-2008). Brasília: Fundação Alexandre de Gusmão, 2009.

CERVO, Amado e BUENO, Clodoaldo. História da Política Exterior do Brasil. Brasília: EdUnB, 2002.

CHEIBUB, Z.B. Diplomacia e construção institucional: o Itamaraty em uma perspectiva histórica. Dados, v. 28, n. 1, p. 113-131, 1985. GALLO, Mel Bleil. Itamaraty cria comitê pela igualdade de gênero e raça. 18 de setembro, 2014. On-line. Disponível em: $<$ http://poderonline.ig.com.br/index.php/2014/09/18/itamaraty-cria-comite-pelaigualdade-de-genero-e-raca/>. Acesso em: 09 nov. 2014.

ENLOE, Cynthia H. Bananas, Beaches and Bases: making feminist sense of international politics. Berkeley: University of Californa Press, 1990.

FRIAÇA, Guilherme. Mulheres Diplomatas no Itamaraty (1918-2011): uma análise de trajetórias, vitórias e desafios. Tese apresentada no $57^{\circ}$ Curso de Altos Estudos do Instituto Rio Branco. Brasília: Ministério das Relações Exteriores, 2012.

HANSEN, Lene. Ontologies, Epistemologies, Methodologies. In: SHEPHERD, Laura J. (Ed.) Gender Matters in Global Politics: a feminist introduction do international relations. London and New York: Routledge, 2010.

MAIA, Melina Espeschit; ALVARENGA, Tainá Guimarães. Marias do Brazil: As mulheres e a diplomacia pelo olhar das Embaixadoras do Brasil na ONU. Itamaraty. Revista Juca, n. 4, p. 28-39, 2010.

MOURA, Gerson. Autonomia na dependência: a política externa brasileira de 1935-1942. Rio de Janeiro: Nova Fronteira, 1980.

OFFEN, Karen. Was Mary Wollstonecraft a feminist? A comparative re-reading of A Vindication of the Rights of Woman, 1792-1992. In: OFFEN, Karen (Ed.). Globalizing Feminisms, 1789-1945. London \& New York: Routledge, 2012, pp. 5-17.

ONU. Organização das Nações Unidas. Carta das Nações Unidas e Estatuto da Corte Internacional de Justiça. On-line. Disponível em: $<\mathrm{http}: / /$ www.onu.org.br/docs/carta_da_onu.pdf>. Acesso em: 10 nov. 2014.

PAIVA, Isadora Campregher. A Escola Feminista nas Relações Internacionais: Bases Teórico-Metodológicas. Trabalho de Conclusão do Curso de Graduação 
em Relações Internacionais da Faculdade de Ciências Econômicas. Porto Alegre: Universidade Federal do Rio Grande do Sul, 2014.

PINTO, Céli Regina J. Feminismo, História e Poder. Rev. Sociol. Polít., Curitiba, v. 18, n. 36, p. 15-23, jun. 2010.

UNIC. Declaração Universal dos Direitos Humanos. Rio de Janeiro, Agosto de 2009. Disponível em: <http://www.onu.org.br/img/2014/09/DUDH.pdf>. Acesso em: 10 nov. 2014.

POSSAS, Lídia Maria Vianna e REIS, Sarah de Freitas. Reflexões feministas acerca das Relações Internacionais. In: MATHIAS, Suzeley Kalil (Org.). Sob o signo de Atena: gênero na diplomacia e nas Forças Armadas. São Paulo: Editora UNESP, 2009.

TICKNER, J. Ann. Feminist Perspectives on International Relations. In: CARLSNAES, Walter; RISSE, Thomas e SIMMONS, Beth A. (Ed.) Handbook of International Relations. Londres: SAGE Publications, 2002.

TICKNER, J. Ann. You just don't understand: troubled engagements between feminists and IR theorists. In: LINKLATER, Andrew (Ed.). International Relations: Critical Concepts in Political Science, Vol.1, p.190-218. London: Routledge, 2000.

WHITWORTH, Sandra. Feminism. In: REUS-SMIT, Christian e SNIDAL, Duncan. (Ed.) The Oxford handbook of International Relations. New York: Oxford University Press Inc., 2008.

Recebido em 24 de abril de 2017. Aprovado em 26 de agosto de 2017. 